\title{
EN LOS ORÍGENES DE LA HISTORIA PENINSULAR CONTEMPORÁNEA; EJÉRCITO Y LIBERALISMO
}

JOSÉ MANUEL CUENCA TORIBIO 


\section{SUMARIO}

1. INTRODUCCIÓN. 2. LA POLÍTICA MILITAR DE 1808-1814. 3. Las milicias. 4. El protagonismo del ejército. 


\title{
EN LOS ORÍGENES DE LA HISTORIA PENINSULAR CONTEMPORÁNEA; EJÉRCITO Y LIBERALISMO
}

\author{
POR \\ JOSÉ MANUEL CUENCA TORIBIO \\ Catedrático emérito de Historia Moderna y Contemporáneo \\ Universidad de Córdoba
}

\section{INTRODUCCIÓN}

Conforme es bien sabido, la ordenación y representación de los poderes públicos regulados en el Código doceañista implicó un brusco corte en la trayectoria del siglo ilustrado, progresivamente inclinada a atorgar a los capitanes generales y gobernadores militares la máxima autoridad en los ámbitos local y regional. Extremo que conduce a recalar obligadamente en la compleja temática de las relaciones entre poder civil y poder militar en los orígenes de la España liberal, cuya cuna se meciera, determinantemente, en Cádiz. La amplitud del asunto y sus infinitas ramificaciones en la trayectoria contemporánea del país hasta las mismas fronteras de nuestro tiempo, determina que todos los afanes por estudiarlo con rigor sean pocos. Estas líneas no van a ser en forma alguna sucedáneo de tales esfuerzos, sino una muy ligera —e indigente- aproximación a tan compleja temática.

Indispensables en su totalidad y en buena parte acertadas las medidas que adoptarán los legisladores antes o después de la discusión parlamentaria del texto constitucional — creación del Estado Mayor o de la Orden de San Fernando (21, agosto de1811), por ejemplo- , la política militar de los legisladores gaditanos —explicitada en el capítulo I del Título VIII, artículos 356-61: «De las 
tropas de servicio continuo»— de la Carta Magna distanció quizá más que unió a la sociedad civil y la castrense ${ }^{1}$. Llamativamente, sin duda. Entre los principales grupos numéricos de las Cortes — tal vez, el segundo tras el eclesiástico- figura el de los militares. Y también de los más pugnaces a favor de la causa liberal en sus vectores más innovadores, por cuanto decir revolucionarios equivaldría a un non sense en un Ejército estamental como el español de la época. Pero incluso en esa mentalidad cabría incluir quizá algunas intervenciones de personajes como el coronel extremeño Fernández Golfín, diputado crucial en coyunturas decisivas para la marcha adelante del programa liberal y de nunca desmentidas convicciones constitucionalistas hasta su fusilamiento con Torrijos en diciembre de 1831.

Sin haber desventrado aún la composición castrense de nuestro primer Parlamento contemporáneo —orígenes, armas, servicios, cultura- es aventurado especular acerca de las razones de su alineamiento, que cuando menos puede decirse que no fue reaccionario y ni tan siquiera demasiado conservador. Procedentes con casi toda seguridad de la nobleza media e hidalguía, tres de ellos pertenecían a la aristocracia más linajuda, cuyas ideas no defendieron en ningún discurso destacado. Otro elemento enigmático más de la Asamblea gaditana, tan fértil en su producción. Cuando es moneda corriente el ponderar el peso inercial ejercido en la guerra por un generalato nobiliario anquilosado en sus reflejos de casta, ninguno de sus representantes en el Congreso se distinguió por la apología de la vieja España. De otro lado, en uno de los sectores más influyentes en el decurso de las Cortes doceañistas, el americano, de cochura, globalmente, progresista, la cifra de mílites fue abultada, con los votos en que ello debió forzosamente de traducirse ${ }^{2}$.

1 «No era nada usual — escribe el autor de una sobresaliente obra sobre el tema- la rapidez con que se sucedieron los escritos y decisiones citadas (de mayo y junio de 1810 en orden a crear el Cuerpo de Estado Mayor). Eran la prueba indiscutible de que las enseñanzas de la guerra reclamaban con apremio la creación del Cuerpo y, de la misma manera, demuestran que dichos documentos no traducían tareas ni resoluciones del momento, sino que se trataba de estudios madurados anteriormente, y de acuerdos previamente adoptados, a los que en esas fechas se les dio forma y valor legal. El prestigio del general Blake y su relación con la Regencia, de la que entró a formar parte poco tiempo después, permitieron llevar a término feliz, en corto plazo de tiempo, una reforma que representó una honda revolución en el estado militar [...]. Las esperanzas puestas en el Cuerpo y la destacada actuación del estado Mayor General tan pronto como entró en funciones, al mismo tiempo que la oposición que despertó en algunos sectores militares y políticos, explica que a los pocos meses de su creación las Cortes del Reino abordasen su organización y atributos, para darles carácter legal y condiciones de permanencia.» E. BALDovín RuIZ, Historia del Cuerpo y Servicio de Estado Mayor. Madrid 2001, págs. 27 y 32.

${ }^{2}$ Desde que en 1914 se publicara la relación de los 66 diputados castrenses de las Cortes de Cádiz poco se ha trabajado con provecho en tal terreno: F. J. MOYA y JimÉnEZ y C. Rey Joly. El 
En fin, por último en dicho orden de cosas, tampoco hay que descartar que la actitud silente e inhibida de la mayor parte del grupo castrense dejase el campo abierto para el triunfo en el rol y status de la profesión castrense de un ideario con el que, quizá, no sintonizaba en su sentir íntimo. Pues, una vez más, conviene tener presente que las Cortes de Cádiz no sólo se redujeron a unos diputados y unos debates, sino que en igual grado, fueron una atmósfera impregnada en sus células más dinámicas y creadoras por un airón de transformación y cambio, que paralizó durante un bienio cualquier conato de resistencia, mucho más, claro está, dentro del recinto parlamentario, donde la presión demagógica de constituyó un dato tan verificable como importante. El predominio de un pensamiento de larvado o expreso antimilitarismo en la Cámara y en la copiosa publicística concerniente a la ubicación de un Ejército derrotado, pero nunca vencido en las fechas indicadas de 1810-1812, en la España del futuro, de un pensamiento de larvado o expreso antimilitarismo, tuvo repercusiones perjudiciales para ese mismo porvenir ${ }^{3}$.

\section{LA POLÍTICA MILITAR DE 1808-1814}

El prejuicio antiautoritario —ostensible, por ejemplo, en significativos pasajes del Discurso Preliminar de la Constitución, de un pacifismo rudimentarioque, según la crítica más documentada sostiene, azemó muchas de sus virtualidades en el terreno de la cooperación de las distintas esferas, limitó igualmente su capacidad de diálogo y entendimiento de la profesión y funciones militares. Pese a los numerosos hechos que parecen contradecirlo, los constituyentes doceañistas no supieron o pudieron sustentar las relaciones del Nuevo Régimen y el Ejército sobre un ancho depósito de simpatía y confianza. Aunque en este cam-

ejército y la marina en las Cortes de Cádiz. Cádiz 1914, sin que los eslabones que engarzan con la historiografía más reciente aporten nada sustantivo en la materia. Sin embargo, lo lábil e imperialista que los autores dan al término de militar — que, $v . g r$. le llevan a incluir en tal clasificación a un diputado como el catalán Capmany, oficial de milicias en la mocedad de una existencia plenamente consagrada al cultivo del intelecto- explica, en alguna medida, los guarismos tan alejados de los suyos que ofrecen autores posteriores como, por ejemplo, Melchor FERnÁNDEZ Almagro — 37 y 9 marinos_- Ramón Solís — 30 y 9 marinos- o J. L. Comellas GarCía-Llera — 46-.

3 «De los doce militares (diputados americanos), ninguno perteneció al grupo servil más radical. Sólo uno se inclinó por el sector conservador y once lo hicieron por el liberal». M ${ }^{\mathrm{a}} \mathrm{T}$. BERRUEZO LEÓN, «Los ultraconservadores americanos en las Cortes de Cádiz (1810-1814)», Revista de Indias, 177 (1986), págs. 172-3. En puridad, fueron 17 los militares americanos presentes en la Asamblea gaditana, bien que sólo de doce se tenga y se atengan al perfil legal y auténtico de diputado. Vid. de la misma autora «La actuación de los militares americanos en las Cortes de Cádiz». Quinto Centenario, 10 (1986), con datos de interés. 
po cualquier reiteración se acogerá con segura indulgencia, no se incidirá aquí, de nuevo, en los numerosos obstáculos interpuestos a la hora de delinear una política militar en una constitución liberal elaborada en el marco de una guerra devastadora y en el tránsito de un modelo de sociedad a otro, cuando las supervivencias del desplazado se mostraban aún con patencia y fuerza ${ }^{4}$.

Rumores y avisos de golpes de Estado, dictaduras pretorianas y rebeldías de altos cuadros castrenses con la caución más o menos explícita de Wellington y su hermano el embajador poblaban el clima político y periodístico de la España fernandina en los meses de redacción de la Carta Magna y su inmediata vigencia. Ni una sola intentona o pronunciamiento debió de abortarse por la simple razón de su absoluta inexistencia. En todo buen gobierno son las realidades las que han de tenerse en cuenta. La desconfianza como principio cosecha siempre en política frutos cedizos. Campañas antimilitaristas de vasto radio y audiencia como la emprendida en Asturias y continuada, con superior eco, en Cádiz por figuras de elevada estatura ética e intelectual pero quizá de menguada talla política como Álvaro Flórez Estrada o Vicente Sancho, la creación, según el ejemplo francés, en el propio texto doceañista de una Milicia Nacional de claro signo anticastrense, por mucho que se insistiere en su carácter de cuerpo armado encargado de preservar

${ }^{4}$ R. L. BLANCO VALDÉs, destacado constitucionalista autor de una excelente tesis doctoral citada en el primer capítulo, opinará que los augurios del eximio asturiano acerca de un despotismo militar, se verían ratificados: «La historia política española de los siglos XIX y XX iba a encargarse de demostrar hasta qué punto las palabras del ilustre liberal asturiano resultaban premonitorias de un futuro en que las fuerzas armadas acabarían por convertirse en uno de los factores perturbadores de nuestra estabilidad constitucional. Una estabilidad que, no casualmente, terminará por conseguirse, al fin, ya acabado el siglo XX, y parece que ahora sin punto de retorno, después de un postrero y fallido intento de golpe de estado militar.» apud J. VARELA SUÁreZ-CARPEGNA (coord.), Álvaro Flórez Estrada (1766-1853), política, economía, sociedad. Oviedo s. a. (2004), págs. 333-4. Más matizada resulta la opinión de un especialista que, si bien extensa, no dudamos en transcribir, por su valor y por la insistencia de las presentes líneas en una cuestión presentada aquí desde un ángulo «heterodoxo» respecto a la posición dominante en la historiografía: «Recapitulemos. Odio exacerbado contra el generalísimo y almirante Godoy, culpable de todos los males nacionales acaecidos en España en los últimos años [....]; tradición civilista de la filosofía política europea —y norteamericana- durante el siglo de la Razón que se ha ido ampliando en la España de Carlos III por la pugna entre «golillas» $\mathrm{y}$ «arandistas»; recelo de los funcionarios de toga contra los uniformados por el papel que han ido adquiriendo desde la llegada del primer Borbón al trono de España; influencia del pensamiento jacobino, que veía en los generales del Antiguo Régimen un peligro para la consolidación del nuevo régimen, negándole, por otra parte, la capacidad militar, profesional, suficiente para enfrentarse con éxito a los ejércitos enemigos...; todo ello conforma la mentalidad de los diputados gaditanos y les hace tomar esa actitud contra el generalato español heredado, buscando la creación de un nuevo ejército, de un nuevo soldado, el ciudadano en armas.» J. CEPEDA GÓMEZ, «La doctrina militar en las Cortes de Cádiz y el reinado de Fernando VII», apud Las Fuerzas armadas españolas. Historia institucional y social. Madrid 1987, III, pág. 16. 
el orden constitucional, no podían contribuir a fomentar una atmósfera de recíproca síntonía entre el régimen liberal y el Ejército, más allá de los deberes de subordinación y obediencia al gobierno de la nación del lado de la institución militar.

No obstante el tinte un tanto ambiguo e indeterminado con que los artículos 362-4 caracterizaba a las Milicias Nacionales y a que, incluso, una vaga filiación con las Milicias Provinciales dieciochescas podría argumentarse para probar también aquí la continuidad del reformismo setecentista con el gaditano, su formación y naturaleza respondían inequívocamente a la idea del ciudadanosoldado propia de la burguesía, de la que venía a ser su brazo armado y escudo protector de sus conquistas político-sociales. «La revolución burguesa se realizó en España. Y la Milicia nacional fue su instrumento», ha podido escribirse en el dintel del estudio — primitiva tesis doctoral- que le consagrase ha ya un tiempo su máximo y ardido estudioso 5 . Los avatares de la implantación del texto constitucional impidieron que el correspondiente Reglamento de la Milicia Nacional no se promulgase hasta 18 de abril de 1814 , por lo que permanecería virtualmente inédito hasta que en el Trienio liberal, época, como se sabe, de profusa y detenida legislación en materia castrense, tras muy pequeñas modificaciones, fuera una de las medidas inaugurales de su primera legislatura, sin que el segundo ensayo constitucional, consecuencia directa de un pronunciamiento militar, adumbrara los perfiles de desconfianza hacia la corporación castrense.

Con plausible afán analítico y manifiesto interés en justificar la obra de las Cortes en la materia y desproveerla de tintes sectarios y alicortos, los estudiosos del tema subrayan el generalizado antimilitarismo de un amplio número de las contestaciones a la «Consulta al país» del otoño de 1809. En las respuestas así connotadas era patente el deseo de un drástico cambio de rumbo en la composición y finalidad de los ejércitos sobre todo, una vez concluida la contienda.

Fiel al mandato desprendido de dichos escritos, la Asamblea gaditana, al formular la necesidad de un servicio militar obligatorio (artículo 391), sentó las bases de una «constitución militar» paralela a la política, señal evidente de la re-

5 «Por otro lado, la dinámica de la guerra provocó situaciones tensas entre las recién creadas academias militares y en los ambientes castrenses más tradicionales. Se tenía la convicción de que la entrada de elementos no nobles en el ejército y la actuación de la autoridad política en asuntos castrenses, como eran los ascensos, afectaba a la misma esencia de la monarquía. De este modo, bien pronto las Cortes se plantearon la necesidad de regular situaciones que demandaban imperiosamente soluciones de largo alcance.» M. Gil MUÑOZ, «Revolución en las instituciones militares de enseñanza durante la Guerra de la Independencia: nuevos centros y pruebas de nobleza», en J. A. Armillas Vicente (coord.), La Guerra de la Independencia..., II, p. 860. 
levancia otorgada a la cuestión castrense (sería, en efecto, de todas las españolas la que mayor latitud le concediera). Ni la idea del servicio militar obligatorio ni la «constitución militar» encontraron desarrollo normativo en sus trabajos y en los de las Cortes Ordinarias; pero no con ello, conforme se ha insistido en el curso de la presente obra, la opinión pública dejó de dar muestras de la atención que le prestaba, mediante una literatura tan abundosa como de ordinario oportunista.

El núcleo sustentador de buena parte de tal pensamiento descansó en el recelo despertado por unas fuerzas armadas autónomas del poder civil liberal y, por onsiguiente, fáciles de convertirse en un elemento opresor de la ciudadanía. Nada, sin embargo, en la tradición nacional confirmaba estas aprensiones. El creador del Ejército español moderno, Carlos III, el «Reformador», fue un monarca en todo «civil», muy alejado de los soberanos guerreros de la casa de Austria y aun del mismo fundador de la dinastía borbónica en España. Ni siquiera con la dictadura — «civil»— de Godoy se detectó una injerencia castrense en cualquier ámbito institucional, sin que, a mayor abundancia, en toda la segunda mitad del siglo de las Luces ningún general obtuviera una particular fama en la sociedad como caudillo o miles gloriosus. De ahí, que las prevenciones hacia un ejército pretoriano significasen un éxito espectacular de la difusión de la literatura pacifista norteamericana y roussoniana, según ya tantas veces se ha indicado en el presente libro. Fieles a sus convicciones y lecturas juveniles, los líderes doceañistas fueron más consecuentes con su ideario que con la realidad española, en una política militar leída invariablemente desde hace más de un siglo y medio a la luz del desgraciado devenir ulterior de la existencia nacional.

Mas, como vuelve a comprobarse por enésima vez, el tema torna a enredarse y conectarse con esencialismos e identidades hoy muy en baja en los mercados historiográficos. Tendencias primarias del pueblo español, su pasión de igualdad a la vez que de admiración por los uniformes, realización de la conquista americana por huestes de origen y conformación medievales alejadas de todo encuadramiento castrense regular y una bien colmada aljaba de cuestiones y problemas similares hacen del asunto un verdadero cajón de sastre para toda suerte de opiniones, dogmas y posiciones. Aquí y ahora, lo único quizá importante sea recordar que Cádiz fue también en él la piedra miliar... ${ }^{6}$.

${ }^{6}$ J. S. Pérez Garzón, Milicia Nacional y Revolución burguesa. El prototipo madrileño. 18081874. Madrid 1978, p. XXV. Un autor en las antípodas doctrinales del precedente, sostendrá de su lado: «Resulta verdaderamente sorprendente que en plena guerra de la Independencia se piense (en los discursos de las Cortes de Cádiz) mucho más que en ganarla en la forma de sostener, frente al rey y su ejército, las libertades individuales y municipales [...]. Por eso dibujan unas milicias provinciales que los liberales gustan llamar nacionales sin más enemigo que el Rey y su ejército, a las 
En una etapa como la referida que asiste en España al nacimiento del periodismo moderno, no es posible dejar de preguntarse sobre la reacción que en la prensa y la bibliografía despertara el grave asunto de las relaciones entre Ejército y sociedad civil, fuerzas armadas y poder político. Según es harto sabido, este fue en diversas ocasiones el tema estrella de la influyente prensa gaditana, con innumerables artículos de corte demagógico, a las veces, y, por lo común, sin porte doctrinal de algún calado. Convencidos de que el Ejército no iba a ser el instrumento revolucionario que deseaban, los tribunos radicales predicaron desde sus páginas soflamas encendidas contra una institución que, convertida en arbitro de la política del país, amenazaría a una «España de ciudadanos libres». Abstracción hecha de posturas maximalistas, la cuantificación del fenómeno —empresa relativamente hacedera y, desde luego, deseable — arrojaría una literatura de espesor si no ideológico sí numérico, palpable reflejo de que los constituyentes no trabajaban en el vacío. Hecho que viene corroborado por la copiosa folletería provocada igualmente por la cuestión.

Con la grafomanía que fuese una de las señas de identidad de la España de Cádiz y en vena del típico arbitrismo hispano, múltiples opúsculos de autoría y paternidad variada — anónima, falsa o auténtica - exponían el punto de vista de sus redactores acerca del método infalible de ganar la guerra o sobre las reformas que habrían de acometerse con la finalidad de hacer del Ejército patriótico un adalid de la nueva sociedad; al paso que otros no menos numerosos desgranaban los padecimientos de los soldados, daban rienda suelta al honor ofendido de ciertos oficiales en sus relaciones con los ingleses o manifestaban la reivindicación de algunos de los innumerables generales destituidos ab irato de sus funciones. Así en la Asamblea — según mas adelante se analizará — como en la prensa y publicística menor de toda la España fernandina, el enconado asunto de las quintas cobrará nuevo vuelo, acentuándose sus perfiles sociales al criticarse vivamente la exención de las clases privilegiadas y acaudaladas. Tema de permanente y tensionada actualidad a lo largo de la segunda mitad del XVIII, los aires de transformación traídos por la desarticulación del Antiguo Régimen harán de la «contribución de sangre» y sus características uno de los temas relacionados con la política y literatura militares más intensa y apasionadamente tratados en la Es-

que insuflan espíritu jacobino a lo ROBESPIERRE — prioridad de la revolución sobre la guerra [...]. Y esto, prácticamente, lo aceptan todos los diputados.» M. Alonso BAQUER, «La doctrina militar de los diputados de Cádiz», Revista de Historia Militar, 33 (1972), págs. 143 y 145.

Y otro escritor castrense afirmará: «Esta dicotomía entre el Ejército y las milicias que se concibieron como fuerza paramilitar al servicio de los partidos liberales iba a producir efectos perturbadores durante casi todo el siglo XIX.» A. MARCHANTE GIL, «Los ejércitos en las constituciones españolas. Un escándalo farisaico», Cuadernos de Encuentro, 84 (2006), pág. 8. 
paña de la guerra de la Independencia, que mostrará con ello otra de sus múltiples líneas de continuidad, no obstante los cambios y mudanzas, con la de la Ilustración ${ }^{7}$.

Todo este alud bibliográfico revelaba indudablemente un vivo interés por una institución —el Ejército - cuyo peso en la marcha del país se intuía creciente y decisivo, con protagonismo desconocido hasta entonces. Como acaba de referirse, no pocos de los liberales más ardientes comprendían los peligros que tal deriva podía comportar un día sobre el sistema constitucional, basado en la omnímoda primacía del poder civil; pero dicha eventualidad no dio paso ni a la autocrítica ni a la mesura demandada por un régimen desasistido de firmes apoyos, obligado por ello a no provocar recelos en una institución en la que, pese a su gran componente nobiliario, no suscitó su advenimiento prevenciones mayores $^{8}$.

Así, sin timoneles respetados ni hoja de ruta clara y bien definida transcurrió la política militar en el crucial sexenio 1808-14. En su dimensión más concreta - la adopción de unas medidas conducentes a la formación de unas fuerzas armadas capaces de garantizar la independencia del territorio nacional—, la España fernandina no logró formularla ni aplicarla con eficacia, con un permanente intercambio de reproches mutuos entre las élites civiles y militares sobre la responsabilidad de la frustración; desencuentro que originaría una recíproca des-

7 Sorprendentemente, el tema sólo merece la siguiente reflexión a su estudiosa más reciente, aplicable más que a la España de Cádiz, a la del constitucionalismo consolidado: «Sistema (el electoral censitario) cuya filosofía — participar en la vida ciudadana — va a permitir tempranas matizaciones: los varones tienen el derecho y la obligación de defender a la Patria, pero, en buena lógica de la época, aquellos que tengan dinero podrán eximirse mediante un canon económico. Los que no dispongan de tal posibilidad económica pagarán con aportación directa, personal. Será lo que muy gráficamente se denominará la contribución, el tributo o el impuesto de sangre». V. FERNÁNDEZ VARGAS, Sangre o dinero. El mito del Ejército nacional, Madrid 2005, p. 17; en las pp. 19-20 se hará la segunda y última alusión al asunto indicado, mediante la reproducción de un texto de un diputado gaditano, Martínez de TejadA. Por desgracia, el viejo pero buido artículo de R. MoRODO y E. DíAz, «Tendencias políticas y grupos políticos en las Cortes de Cádiz y en las de 1820», resulta muy opaco y menesteroso en todo lo concerniente al mundo castrense, Cuadernos Hispanoamericanos, 201 (1966), págs. 235-82.

8 «¿Hasta qué punto se hizo efectivo el alistamiento popular ordenado por las Juntas? Aunque al principio éstas cuentan con el entusiasmo y la euforia popular y parecía que los alistados se encuadrarían voluntariamente en el ejército, tuvieron que recurrir al sistema de quintas (por ejemplo, en Cataluña, Galicia, Asturias, Extremadura), incluso en fechas posteriores (dic. de 1809 y nov. de 1810), lo que provocó una militarización creciente de la población y a su vez un cierto rechazo a este sistema, expresado en el retraso en la incorporación al ejército o en las frecuentes exenciones fraudulentas que se producían». A. Moliner DE PRADA, Pueblo y ejército en la guerra de la Independencia..., pág. 35. 
confianza nunca realmente desaparecida y cuya gestación en la España de Cádiz cabe atribuirla primordialmente a los estratos políticos e intelectuales?

En un plano más general, el contenido en lo que habría de conocerse al otro cabo de la centuria como «la cuestión militar», sin desmerecer los afanes de las Cortes por suprimir lastres y agilizar el funcionamiento de la institución castrense y de los que más adelante se harán cumplida mención, se constata los pocos frutos de una tarea alicorta y sin vigor, debido a su enfoque parcial e ideologizado. Mal que bien, constreñida por el ambiente, según declarara uno de los primates de liberalismo avanzado, Agustín de Arguelles, el Parlamento gaditano dio un marco dilatado y acertó a encarrilar sin mayores polémicas — hasta las Cortes de 1869 no se confesaría ateo ningún representante del pueblo español- las siempre difíciles relaciones de la Iglesia y el Estado. Sin embargo, la cuestión militar, no menos vital para una organización del poder y convivencia modernos, quedó de facto aplazada sine die. El pronunciamiento de Riego y la identificación del Ejército con la causa liberal a partir de la primera guerra carlista pospusieron durante largo tiempo — en realidad, hasta la Segunda República - el enfrentamiento del tema preterido en Cádiz: la incardinación de las instituciones castrenses en un Estado de Derecho, sin violencia legal ni vejación institucional, como reflejo de una cultura ciudadana de cordial entendimiento de la naturaleza suprapartidista de unas fuerzas armadas, indispensables en un contexto internacional, en el que la guerra sería, desgraciadamente, por mucho tiempo la ultima ratio...

Fatalmente para los destinos de la nación, los legisladores gaditanos convirtieron al elemento castrense en chivo expiatorio de errores y reveses colectivos. Debido a una actitud en algún punto comprensible, el primer régimen constitucional acusó al Ejército y a la Marina de la situación de impotencia a que estuvo reducida la España fernandina en el bienio crucial 1810-12, en el que las

9 «La subordinación del poder militar, es decir, del mando supremo castrense al poder civil, quedó simbolizada en el constitucionalismo gaditano [...], en la cláusula que reconocía al Rey, al titular del poder ejecutivo del Estado, el mando de los ejércitos y armadas. De igual forma, los distintos textos reglamentarios que regularon con carácter provisional a todo lo largo de 1810-1814 el funcionamiento, acciones y relaciones con otros poderes del ejecutivo —el Consejo de Regencia-, recogían aun a pesar de sus diferencias en este ámbito [...], ese mismo principio de sometimiento de la cúpula militar a las autoridades civiles. [...] Pero si esta subordinación político-administrativa adquirió consagración jurídica sin que en torno a la misma se suscitasen mayores controversias, no ocurrió lo mismo con la sujeción del mando militar a los órganos civiles en el ámbito más estricto de la dirección técnico-militar de la defensa y de la guerra. De ello da buena cuenta el proceso de creación provisional y definitiva consolidación legal del Estado Mayor General como órgano supremo directivo militar». R. L. BlanCo VAldÉs, Rey, Cortes y fuerza armada..., págs. 253-4. 
Cortes llegaron a simbolizar la pervivencia del espíritu nacional. Sin tradición alguna de pretorianismo en una monarquía como la borbónica, en la que las fuerzas armadas no desbordaron jamás las fronteras estrictas de su función, las veleidades cesaristas de algunos pocos generales, las maquinaciones anticivilistas de otros, también en muy escaso número, y los desmanes despóticos de dos o tres altos mandos justificaron a los ojos de la vanguardia liberal un antimilitarismo primario, reflejo de un prejuicio doctrinal y un fácil método de defensa, declinando sobre el Ejército responsabilidades colectivas.

Proceso, pues, como se decía, de pesarosa concatenación en la forja de la España contemporánea. Lo que en Alemania se erigió en fundente y elemento identificador de la nacionalidad, en Inglaterra — la Flota—, símbolo de exaltación de los valores de la misión histórica de su pueblo, y en Francia, pasado el cabo de las tormentas de la III República, en garantía de los destinos del país, en España llegó a ser piedra de división ${ }^{10}$.

\section{LAS MILICIAS}

Sin una política medianamente definida y aplicada y con unas fuerzas armadas en permanente trance de reordenamiento, es natural recalar una y otra vez en la cuestión que ocupa, conforme ya quedó apuntado, un lugar privilegiado a la hora de enjuiciar el resultado final de la guerra de la Independencia.

La organización, el método, la disciplina y la constancia corrieron fundamentalmente a cargo de los ingleses, a los que, en buena lógica, cabe atribuir gran parte si no la exclusividad de la victoria contra los franceses, contando Wellington como auxiliares poderosos a los guerrilleros. Versión heterodoxa en los círculos más extensos del país — canónica, en muy reducidos ámbitos del pasado y, sobre todo, del ayer reciente—, la de más ancha y prolongada circulación por los espacios culturales de España contemporánea semeja ajustarse, pese a todo, más a la realidad. Bernardo López fue sin duda un poeta prosaico, pero acertó a encarnar la conciencia profunda de una nación reencontrada consigo misma en la honda crisis de 1808. La repristinización de algunas de las fuentes de su asombrosa vitalidad en aquel trance y en decenios posteriores sólo puede explicarse a dicha luz.

${ }^{10}$ Provocando las iras de Azaña y de algunos de sus modernos escoliastas — Juan GoYtisolo, ad exemplum-, Galdós, con sus cantos epinicios al Ejército decimonónico como heraldo de las libertades, popularizó entre la opinión de su tiempo la imagen de unas fuerzas armadas íntegramente comprometidas con el progreso de la nación. Cf. J. M. CuEnCA Toribio, Historia y literatura, Madrid 2004 
Por encima de las cifras llamativas de prófugos y desertores, del inflexible repudio de ciertas regiones — el Principado catalán en cabeza ${ }^{11}$ — al servicio militar obligatorio o regular, del caos en el que se debatieron en no pocas ocasiones el mando militar y la organización castrense, de la desesperanza y el escepticismo sembrados a manos llenas por los profesionales del catastrofismo, aliados muchas veces con la cruda realidad de los hechos, el pueblo español no cejó de nutrir, más de grado que por fuerza, las unidades de un Ejército regular que en ningún momento se dio por vencido al sentirse eco y portavoz en los campos de batalla de una vieja nación para la que la independencia era el valor supremo. El que, conforme acaba de apuntarse, en la región en que más ahincado estaba el rechazo al servicio militar fuesen sus milicias tradicionales de miqueletes y somatenes las más nutridas y acaso también las más combativas entre las de su género, descubre con nitidez cómo el espíritu del pueblo animó por encima de cualquier otro impulso la resistencia española contra el francés.

\section{EL PROTAGONISMO DEL EJÉRCITO}

Lo expuesto hasta aquí tan apresurada como chafarrinescamente acerca de la evolución de la trayectoria en los capítulos inaugurales del sistema constitucional será, con todo, quizá suficiente para contextualizar con cierta propiedad el

11 «Les relacions entre el poblé i l'exércit es varen deteriorar como a conse-qüencia deis abusos comesos al camp pels soldats, sometents i miquelets. La població catalana es va resistir a integra-se dins l'exércit regular comha demos-tren els pasquins contre eles quintes i les continúes desercions deis soldats [...]. Miquelets i sometens, d'arrelament tan pregón en la tradició $*_{i}$ la historia de Catalunya, van ser lárma de xoc enfront de les tropes franceses des del primer moment. Es tractava d'un sistema diferent a les quintes, tan odiat peí poblé cátala». A. Moliner PradA, la Catalunya resistent a la dominació francesa: la Junta Superior de Catalunya (1808-1812), Barcelona 1989, págs. 10 y 57. Otro relevante investigador no catalán pero muy incardinado, como el anterior, en los círculos historiográficos del Principado, afanoso, con ingenio y erudición envidiables, en demostrar lo indemostrable y acercarse, como dirá otro con-temporaneísta de la misma generación de los susomentados, E. CANALES, a una «visió mes real de la Guerra del Francés», nos dirá aquí con pertinencia: «Y, sobre todo, las Partidas patrióticas garantizaban a sus componentes la permanencia de sus individuos en el territorio donde se habían formado. Esta cuestión, que, como sabemos, pudo ser esencial para la movilización popular contra Napoleón, lo había sido y seguía siéndolo para la aceptación de cualquier forma que estableciera — aunque subrepticiamente- la militarización de la población civil. En efecto, cuando en 1811 circuló en Cataluña el rumor de que los Tercios de Partidas Patrióticas iban a ser destinados fuera del Principado, sus individuos comenzaron a abandonarlas precipitadamente». L. ROURA, «Guerra pequeña y formas de movilización armada en la guerra de la Independencia: ¿tradición o innovación?», Trienio, 36 (2000), pág. 87. 
golpe de Estado dado en Valencia en mayo de 1814 por el Capitán General Francisco Javier Elio, que implicara el retorno al absolutismo en la todavía idolatrada figura de Fernando VII, al mismo tiempo que la apertura de una senda recorrida con asiduidad por el ejército español contemporáneo: la de los pronunciamientos.

Así, pues, el paralelismo que, con sobrada exactitud, se traza en ocasiones entre la andadura portuguesa e hispana en los siglos XIX y XX no se refrende, al menos por entero y de forma sustantiva, en el plano de sus respectivas fuerzas armadas. La absorbente y crucial intervención del estamento castrense en los destinos de la contemporaneidad española no encuentra igual papel la portuguesa. La participación, el protagonismo del Ejército en la política lusa de las mencionadas centurias fue, por supuesto, muy peraltado; pero jamás o casi nunca con la intensidad y capacidad decisoria de su homónimo español. Según es harto sabido, los pronunciamiento y caudillismos militares no faltaron en el Ochocientos portugués, dejando en él, a las veces, huella determinante y prolongada; y en el Novecientos la caída de la monarquía de los Braganzas, la implantación de la dictadura salazarista y aun el propio inicio del actual régimen democrático se debieron en medida más o menos descollante pero siempre destacada a la activa presencia de las fuerzas armadas. En el mismo siglo, Sidonio Paz y el general catalizaron por un tiempo — breve, en conjunto- las esperanzas de extensos sectores de la vida nacional, a manera de miles gloriosus que introduciría a la nación en una etapa de bienandanza y prosperidad.

Con ser, pues, sin duda — se volverá a repetir_-, muy densa la tonalidad castrense de los dos últimos siglos de vida lusitana en manera alguna cabe compararla con la española. Con todo rigor, el estudioso más sobresaliente de la historia comparada de ambos países en su itinerario contemporáneo, D. Jesús Pabón y Suárez de Urbina, denominó al liberal «el régimen de los generales»; y aunque en ningún caso la preponderancia y ascendiente militares en constitucionalismo ochocentista se trocaron en despotismo o cesarismo, el pretorianismo se erigió en dato mayor y referencia clave de la sociedad y política españolas a lo largo de casi doscientos años. Igual y ni tan siquiera semejante rol no caben atribuirlos a los generales y situaciones imbuidas por el talante e intereses de las fuerzas armadas que se testan en la trayectoria lusitana de idéntica cronología.

La guerra de la Independencia a uno y otro lado del Tajo, punto de partida indiscutible de la contemporaneidad de ambos pueblos peninsulares no dejó igual herencia en uno y otro país en el tema ahora analizado. Una vez más, Inglaterra representó un papel axial en el rumbo de la nación portuguesa, al fomentar, en una coyuntura propicia al protagonismo de los militares, el fermento de civilidad y peralte de la sociedad característicos de la modernidad británica. El 
Marqués Do Douro, el Duque de Wellington, descepó en el ejército luso-británico cualquier brote de liderazgo o caudillismo castrense en las tropas lusas bajo su mando e idéntico camino siguió su lugarteniente Beresford en todo el tiempo de su mandato regencial.

Pero no tan sólo, conforme resulta bien conocido, el legado o impronta ingleses en las fuerzas armadas portuguesas participantes con denuedo y brillantez en Peninsular War, el elemento determinante de su subordinación en los tiempos posteriores del nacimiento y consolidamiento del sistema constitucional al poder civil encarnado por la Corona y las instituciones liberales, y de su escasa inclinación a crear «un poder militar» basado, en última instancia, en la fuerza las bayonetas. La Monarquía — en especial, una vez acabada la guerra civil entre D. Pedro y Doña María, de un lado, y D. Miguel, de otro-y, sobre todo, las elites burguesas tuvieron en el Portugal decimonónico una vitalidad e influencia sociales de las que carecieron en España la Corona y la nueva clase dirigente. Aquí, en el solar hispano, el afianzamiento del liberalismo debióse, en ancha medida, a la decantación del Ejército a favor de la causa constitucional, desprovista de apoyo masivo en las capas populares — la población agraria del país, en casi integridad - y sin el respaldo de una burguesía poderosa y militante. En suelo luso, las tropas adictas al liberalismo se incluyeron entre los factores decisivos del triunfo sobre las miguelistas, pero sin el monopolio y trascendencia usufructuados en el mismo trance por el Ejército español.

Title:

IN THE ORIGINS OF CONTEMPORARY PENINSULAR HISTORY; ARMY AND LIBERALISM.

\section{Summary:}

1. Introduction. 2. The military policy of 1808-1814. 3. The military services. 4 . The protagonism of the army.

\section{Resumen:}

El trabajo versa sobre la compleja temática de las relaciones entre el poder civil y el poder militar en los orígenes de la España liberal. El numeroso sector militar de las Cortes de Cádiz, adicto mayoritariamente a la causa liberal, apoyó la puesta en marcha del programa reformista de ruptura con el Antiguo Régimen. La idea burguesa de ciudadanosoldado, garantía de sus conquistas político-sociales, impregna la regulación de las Milicias Nacionales en la Constitución de 1812. Sin embargo, la Carta Magna no resolvió la incardinación de las instituciones castrenses en un Estado de Derecho, sin violencia legal ni veja- 
ción institucional, como reflejo de una cultura ciudadana de cordial entendimiento de la naturaleza suprapartidista de las fuerzas armadas, quedando preterida esta nuclear tarea hasta la Constitución española de la II República.

\begin{abstract}
:
The work turns on complex thematic of the relations between the civil power and the military power in the origins of liberal Spain. The numerous military sector of Cortes of Cadiz, addict mainly to the liberal cause, supported the beginning of the reformist program of rupture with the Old Regime. The citizen-welding bourgeois idea of, guarantee of its conquests political-partner them, impregnates the regulation of the National Military services in the Constitution of 1812. Nevertheless, the Magna Carta did not solve the inclusion of the military institutions in a State of Right, without legal violence nor institutional humiliation, like reflection of a citizen culture of warm understanding of the suprapartisan nature of the Armed Forces, being preterida this nuclear task until the Spanish Constitution of II the Republic.
\end{abstract}

\title{
Palabras clave:
}

Ejército, liberal, Milicias Nacionales, Constitución de Cádiz.

\section{Key words:}

Army, liberal, National Military services, Constitution of Cadiz. 